\title{
11
}

\section{Faculty Development that Transforms the Undergraduate Experience at a Research University}

\author{
Kathleen S. Smith \\ University of Georgia
}

Rethinking the undergraduate experience at research universities is a necessary goal for the new millennium according to the Boyer Commission on Educating Undergraduates (1998). Faculty development efforts provide a starting place for a transformation of the traditional teaching-learning model. This essay describes the faculty development support structure included in a FIPSE sponsored program to promote learning by inquiry. The Center for Undergraduate Research Opportunities (CURO) at the University of Georgia meshes teaching and research so that undergraduate students become participants in the strengths of a research university by becoming part of a community of learners.

\section{INTRODUCTION}

$\mathrm{R}$ esearch universities have the potential to offer a virtually matchless education because of their wealth of intellectual power and resources, according to the Boyer Commission on Educating Undergraduates in the Research University (1998). However, most undergraduates are not benefiting from the strengths of the research university, including the opportunity to participate in research and to interact with active research faculty and graduate students. This essay describes a FIPSEsponsored project which affords undergraduates, research faculty, and graduate students a mechanism to become a community of learners sharing their particular expertise and insights with each other. 


\section{The Center for Undergraduate Research Opportunities}

In 1997, the honors program, in cooperation with the Office of Instructional Support and Development and the Office of Sponsored Programs of the Vice President for Research at The University of Georgia, submitted a proposal to the Foundation for Improving Post Secondary Education (FIPSE) entitled "Synergizing Research and Education: A Center for Undergraduate Research Opportunities." The proposal outlined a mechanism to encourage a more learner-centered university by establishing a Center for Undergraduate Research Opportunities (CURO). CURO's purpose is to enhance opportunities for undergraduates to undertake individual research, to support faculty initiatives to make a role for undergraduate students in their research, and to provide graduate students serving as research assistants with training in the mentoring and management of student research personnel. The proposal was funded by FIPSE, and CURO activities began in the fall of 1997.

\section{CURO ACTIVITIES}

\section{Faculty Development Efforts}

The Office of Instructional Support and Development (OISD) provides the mechanism to communicate with faculty and graduate students who might be interested in working with an undergraduate. Well-established new faculty orientations, teaching assistant (TA) workshops, teaching support seminars, OISD publications, and web pages advertise the CURO opportunity. OISD staff members also coordinate the CURO TA support seminars.

Each fall, new faculty participate in a two-day orientation conducted by the faculty development office which includes an invitation to join the CURO faculty. These faculty agree to accept undergraduate researchers and to provide opportunities for undergraduates to work on a portion of their research or to provide mentoring in research skills for a student who may be working on an independent research project.

Experienced research faculty are also invited to teach one of the courses undergraduates might take to develop their project. These courses provide a forum for experienced research faculty to guide a group of undergraduates in the development of a research question and in setting up a research project. The courses include guidance in writing a project abstract, and in developing a bibliography, an annotated outline of the project, and a hypothesis. The class members work on identifying a methodology for each project and a project time line. Each member has 
a fully developed research proposal by the end of the class. Once projects are established, research faculty are the teacher of record for an independent credit seminar where individual students work one-on-one with the faculty member and a graduate student on an independent project.

Individual mentoring of undergraduates in this setting is fairly costly in terms of time allocation, so an essential element of the Center for Undergraduate Research Opportunities is a program to develop mentoring skills for graduate students so they may effectively help the faculty member work with the undergraduate. These graduate student scholars constitute the unique strengths of a research university. Those who are awarded assistantships are usually the best and brightest students in their discipline and afford undergraduates a wonderful source of inspiration and expertise. Since graduate teaching and laboratory assistants are very involved in the lower division courses, they can help undergraduates identify areas of interest and faculty members who might have research opportunities. Graduate students can suggest the many avenues to pursue a research project including internship possibilities, credit classes, and individual research interests. In addition, they can guide students in the process of participating in the Center for Undergraduate Research Opportunities (Figure 11.1).

This graduate assistant mentoring is crucial to get projects started and to manage the mechanics of the various stages of the project. Graduate students also act as the liaison to the faculty member of the team and, when necessary, provide opportunities for the undergraduate to interact directly with the faculty member as well as keep all members of the team updated on the progress of the research. Patricia Cross (1998) has documented the value of working in this type of learning community and argues they have a sound philosophical, research, and pragmatic base. The 1998 Boyer Commission report also endorsed learning communities structure with the statement that participants are more experienced than others, some are far along the way toward academic maturity, and some are not. Still, all are committed to the exploration of defined areas of knowledge, and in the university, as envisioned here, they work together. Faculty members, graduate students, and baccalaureate students all bring their particular combinations of energy, imagination, experience, and accumulated knowledge to bear.

\section{TA Development Support Structure}

An essential component of the CURO support effort is to provide a mechanism for graduate students to broaden their graduate experience as they mentor undergraduates. During the first two years of the project, the 
FIGURE 11.1

\section{Undergraduate Research Opportunities}

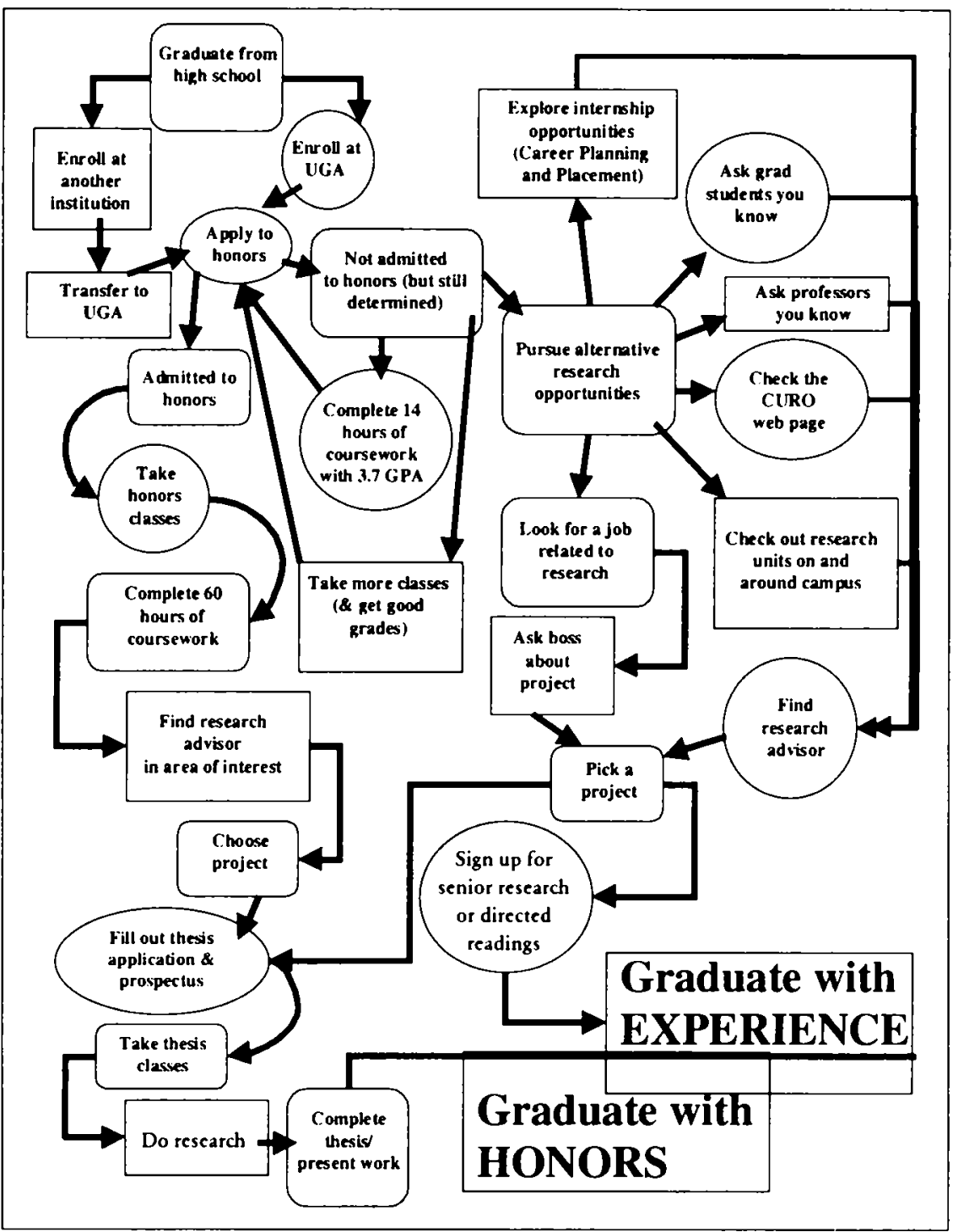


CURO TAs identified a number of reasons graduate students would benefit from the mentoring experience (see Figure 11.2). For graduate students preparing for academic careers, this kind of experience reflects future faculty roles (Gaff \& Lambert, 1996). Supervision of projects also provides leadership opportunities, which can prepare graduate students for roles in business and the private sector.

Since the role of graduate students as members of the learning community is so crucial to the feasibility of widespread undergraduate research opportunities, we have focused on providing extensive support for the graduate assistant mentoring role. An annual fall workshop introduces the Center for Undergraduate Research Opportunities, outlines the benefits of developing this aspect of university scholarship, and details mentoring strategies which have proven successful in working with undergraduates. CURO TAs who have successfully mentored undergraduates in the research setting lead this workshop and provide a source of inspiration for new graduate teaching and laboratory assistants as they begin their graduate program.

\section{CURO TA Seminars}

The annual fall workshop is followed up by a series of CURO TA-led seminars to address discipline-specific issues. We have made efforts to select CURO TAs in both the sciences and humanities. Early in the fall semester, graduate students are invited to attend seminar sessions led by experienced CURO TAs. These include discussions on teaching undergraduates the techniques and safety issues needed to work in a laboratory, as well as sessions on time management, improving writing and independent thinking skills, and teaching the scientific process. We also address techniques to involve students in research, to start a student on a research project, and to teach library research skills. All sessions include discussions on the importance of technical and scientific preparation before beginning research, the ethics of research, and expectations for accurate documentation. Most important for the graduate students' future careers are discussions with the experienced CURO TAs on the constructive, supportive, and creative management of research that encourages the learning-by-inquiry concept of teaching.

Graduate assistants who complete these seminars and who successfully supervise undergraduates are invited to apply for an additional fractional graduate assistantship of $\$ 500$. These graduate students also participate in shaping and delivering the CURO TA seminars the following fall. 


\section{Figure 11.2}

\section{Good Reasons for Graduate Students to Mentor Undergraduate Researchers}

1. Provides a forum for the graduate student to work as a team with an undergraduate and a faculty member

2. Increases graduate student involvement with the research of the discipline

3. Helps the graduate student clarify their own research techniques

4. Provides an opportunity for an undergraduate researcher to explore a topic which could inform the graduate student's research or technique

5. Gives graduate students an opportunity to refine how they teach someone about their discipline

6. Creates an opportunity to work with an undergraduate in a mentoring role

7. Highlights and makes public the graduate student's expertise in the discipline

8. Reflects mentoring roles in future academic positions or the public sector

9. Enlarges the dimension of graduate preparation and provides an opportunity to document a role which might attract future employers

10. Could result in a publication

11. Helps graduate student explore writing strategies and the writing expectations in the discipline

12. Helps graduate student identify time management strategies which aid in meeting deadlines and in project completion

13. Contributes to synergizing research and teaching

14. Capitalizes on the strengths of a research university in having the best and brightest in the discipline (graduate students) interacting with undergraduates

15. Helps future employers identify the graduate student as someone willing to share your knowledge with others 


\section{Credit Classes}

Regularly scheduled teaching support classes for graduate students have added a session on mentoring undergraduates in the research setting. $A$ class web page provides sample projects, a description of a variety of research methods, and writing resources to help guide students in writing up the results. Other class sessions focus on the benefits of learner-centered approaches to guiding undergraduate learning. Each graduate assistant is asked to identify an aspect of their discipline or research in which undergraduates might be encouraged to conduct independent research.

\section{Publications}

The CURO TA opportunities and resources for mentoring undergraduates are also outlined in The teaching assistant newsletter and TA handbook received by every graduate teaching and laboratory assistant. CURO TAs also helped to adapt a mentoring brochure originally developed for mentoring graduate teaching assistants (Smith, 1995). This brochure uses basic mentoring concepts and applies them to the process of effective project management (see Figure 11.3) and effective undergraduate mentoring (Figure 11.4), (Smith \& Klaper, 1999).

Effective project management (see Figure 11.3) involves encouraging undergraduates to work on a research project and helping them connect their research interests to existing faculty research or to individuals who can help them develop research skills. TAs are frequently asked to clarify roles, responsibilities, and support services for undergraduates. This kind of pre-project planning is essential to developing a sound project. For example, helping undergraduates to identify library sources, databases, and writing support helps immensely in getting students started on projects. A detailed written project description clarifies, early in the process, expectations and procedures for all members of the team. A list of the faculty, TA, and peer support structure also identifies the key people who can assist with the development of the project. To avoid unnecessary misunderstandings or accidents, policies related to safety and equipment use should also be discussed and posted. Frequent contact with the undergraduate to discuss specific project outcomes and to help resolve any problems is essential. This is where TAs can encourage faculty involvement and expertise.

Effective undergraduate mentoring (see Figure 11.4) encourages the best young scholars in a discipline, represented by an institution's graduate students, to interact with individual undergraduates. Lowerdivision classes are an ideal introduction to the culture of a discipline as 
Figure 11.3

\section{Mentoring Undergraduate Academic Projects Effective Project Management}

\begin{tabular}{|c|c|c|}
\hline $\begin{array}{l}\text { Pre-project } \\
\text { Planning }\end{array}$ & $\begin{array}{c}\text { Detailed Project } \\
\text { Description }\end{array}$ & $\begin{array}{c}\text { Frequent } \\
\text { Contact }\end{array}$ \\
\hline $\begin{array}{l}\text { Includes a discussion of: } \\
{ }^{*} \text { Ways to identify under- } \\
\text { graduates who may be } \\
\text { interested in a project } \\
\text { and ways to link proj- } \\
\text { ects to interests of TAs } \\
\text { and faculty in develop- } \\
\text { ment stage } \\
\text { *Supervision of faculty } \\
\text { roles, responsibilities, } \\
\text { benefits } \\
\text { *TA role description, re- } \\
\text { sponsibilities, benefits } \\
\text { *Undergraduate eligibil- } \\
\text { ity, responsibilities, } \\
\text { benefits } \\
\text { *An orientation to sup- } \\
\text { port services for under- } \\
\text { graduates developing } \\
\text { projects including sam- } \\
\text { ple projects, contact } \\
\text { phone number, email, } \\
\text { and web sites of re- } \\
\text { sources } \\
\text { *Details of the process to } \\
\text { sign undergraduate up } \\
\text { for project } \\
\text { *Issues to address with } \\
\text { undergraduate to start } \\
\text { the project }\end{array}$ & $\begin{array}{l}\text { Includes: } \\
\text { *Written project descrip- } \\
\text { tion } \\
\text { *Written description of } \\
\text { project responsibilities } \\
\text { and priorities } \\
\text { *A list of project support } \\
\text { systems including fac- } \\
\text { ulty contact, peer men- } \\
\text { tors, graduate assistant } \\
\text { help } \\
\text { *Discussion and written } \\
\text { description of univer- } \\
\text { sity policies that di- } \\
\text { rectly affect project and } \\
\text { relevant issues of safety } \\
\text { and liability } \\
\text { *A written explanation of } \\
\text { departmental policies } \\
\text { on the use of equip- } \\
\text { ment }\end{array}$ & $\begin{array}{l}\text { Includes: } \\
\text { *Regular meetings to dis- } \\
\text { cuss progress and for- } \\
\text { mulate strategies for } \\
\text {-time management } \\
\text { - organizational } \\
\text { skills } \\
\text { - writing skills } \\
\text { *Opportunities for peer } \\
\text { mentoring to provide } \\
\text { undergraduates with } \\
\text { peer support in devel- } \\
\text { oping their project } \\
\text { "Access to faculty and } \\
\text { TAs to discuss specific } \\
\text { project issues }\end{array}$ \\
\hline
\end{tabular}

undergraduates interact with their graduate assistants and faculty. Effective involvement in the discipline is crucial in encouraging their interest in a particular field. As interests develop, graduate assistants and faculty must be sensitive to the diverse needs of undergraduates as they help develop a project. Professional roles must be clearly outlined and a mechanism to communicate accomplishments and help in trouble shooting problems is essential to an atmosphere of mentoring, collaborating with, and challenging undergraduates in their intellectual development. 
FIGURE 11.4

\section{Mentoring Undergraduate Academic Projects Effective Undergraduate Mentoring}

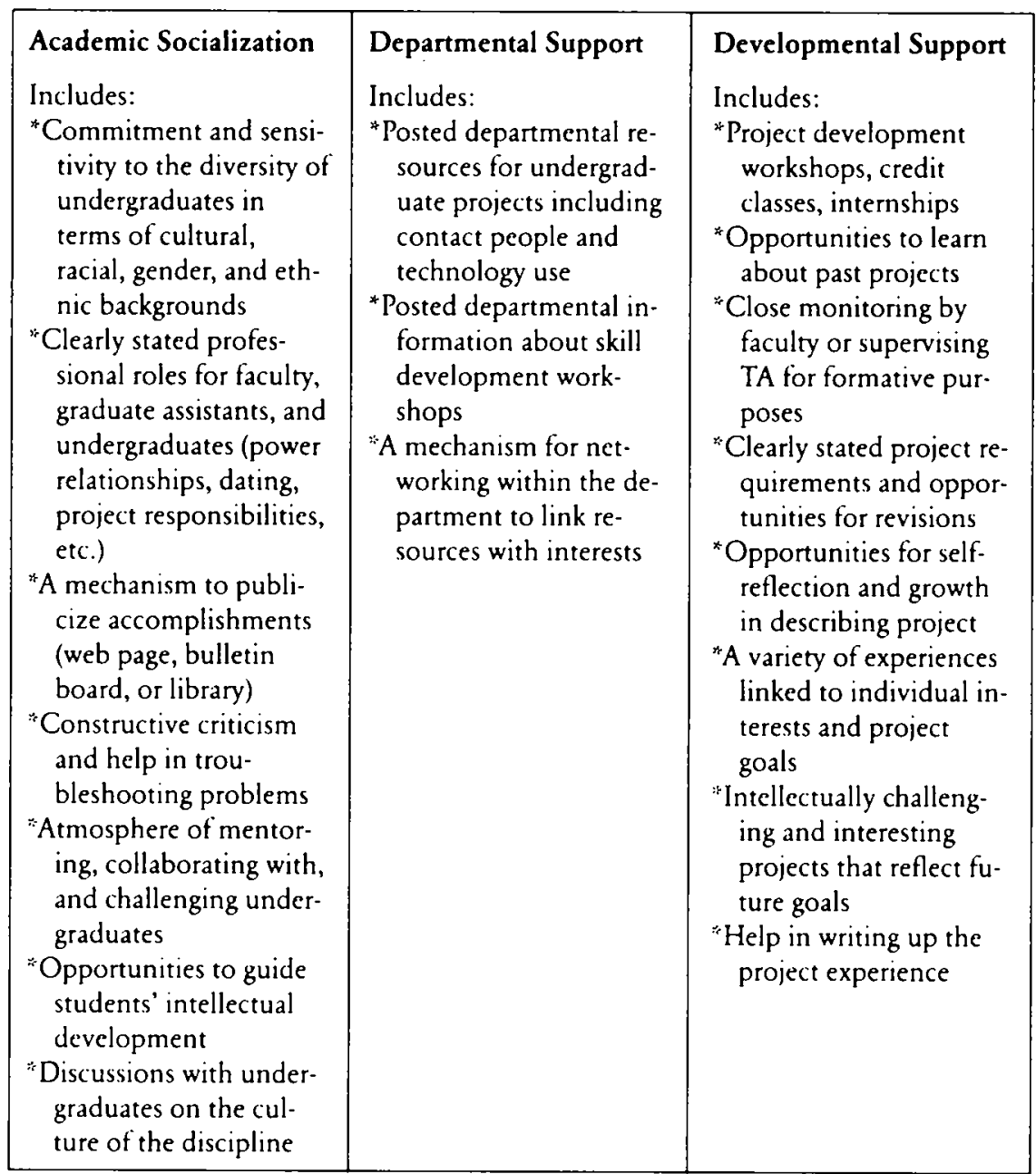

Graduate students provide the link to departmental support of the project and help model the culture of the discipline as they work with the undergraduate. Graduate assistants can also help the undergraduate identify experiences that will provide developmental support for their project. For example, they can identify past projects which may be helpful, and the classes and seminars an undergraduate can take to help develop their project. Graduate students also monitor the progress and help to identify aspects of the project that may need to be developed. Finally, 
graduate assistants can provide the structure for writing up the project in a format that reflects the style of the discipline.

\section{Evaluation}

Before the establishment of the CURO effort, less than 20 honors theses were normally completed each year. An indication of the effectiveness of the CURO initiative is the increase in the number of students who attempt to complete a research project and write an honor's thesis. Currently there are 151 undergraduates enrolled for independent research credit. Forty-eight undergraduates completed their theses in the spring of 1999. More than 350 faculty have joined the CURO faculty willing to take on an undergraduate research student, and faculty are increasingly involving undergraduates in their funded research efforts. In addition, graduate students are actively seeking an opportunity to work with undergraduate students, which is another indicator of the effectiveness of the program because it provides an added dimension to graduate preparation. Graduate students completing the CURO TA program and successfully participating in the supervision of an undergraduate research project are provided with certification that enhances their professional portfolio. We will continue to assess the value of the preparation we provide for graduate students in supervising undergraduates.

Through the supervision of an outside evaluation consultant, we are also tracking participants to determine the subjective impact of work in faculty research programs and objective changes of undergraduate thinking about early career trajectories. In addition, we are tracking the number of undergraduates involved in extramurally supported research.

\section{Conclusion}

Adding the elements of managing and mentoring undergraduates in the research setting to the workshops, credit classes, and seminars has added an important dimension to faculty development and graduate preparation which has the potential to transform the undergraduate experience at a research university. The CURO initiative has made it possible to dramatically increase the number of undergraduates working on research projects, so funding for CURO will continue from the university beyond the initial FIPSE-sponsored program in order to further the success of the first three years of the project. The Office of Instructional Support and Development will continue to include the concept of undergraduate 
research and learning communities in its faculty and TA development efforts.

To implement this type of faculty development effort on other campuses, it is important to focus on the early inclusion of new faculty, the involvement of experienced research faculty, and the training of graduate assistants in the concept of learning communities. New faculty orientations and seminars can introduce undergraduate research as part of the campus culture. Senior faculty can be included by special invitation in a list of faculty willing to mentor a project. Capitalizing on the strengths of a research university, graduate assistants can be encouraged to provide the mechanism for large numbers of research faculty to work as a team with undergraduates. Universities might also work closely with departments that already conduct some undergraduate research to identify graduate students who might help other graduate students in mentoring individual undergraduates and in creating materials which faculty and TAs might find helpful. By making public the advantages of including this type of activity as part of graduate preparation, departments may be more willing to encourage all of their faculty and graduate students to participate in research teams. It can also be used as a recruitment incentive because undergraduates have better access to faculty via the graduate student and have an opportunity to work with the best young scholars in their disciplines. Including departments that have not been involved in this type of research by special invitation and recognition if they participate also involves more of the university. Supporting this kind of learning community (Cross, 1998) provides an effective means of managing projects and mentoring undergraduates and has the potential to transform the undergraduate experience at a research university.

\section{REFERENCES}

Boyer Commission on Educating Undergraduates in the Research University. (1998). Reinventing undergraduate education: A blueprint for America's research universities. Lawrenceville, NJ: The Carnegie Foundation for the Advancement of Teaching.

Cross, P. K. (1998). Why learning communities? Why now? About Campus, 3 (3), 4-11.

Gaff, J. G., \& Lambert, L. M. (1996, July/August). Socializing future faculty to the values of undergraduate education. Change, 38-45.

Smith, K. S. (1995). Managing and mentoring graduate teaching assistants at the 
University of Georgia. In T. A. Heenan (Ed.), Teaching graduate students to teach: Engaging the disciplines (pp. 101-106). University of Illinois at UrbanaChampaign, Office of Conferences and Institutes.

Smith, K. S., \& Klaper R. D. (1999). Graduate assistant involvement in transforming the undergraduate experience at research universities. The Journal of Graduate Teaching Assistant Development, 6 (2), 95-102.

\section{Contact:}

Kathleen S. Smith

Senior Academic Professional

Office of Instructional Support \& Development

Instructional Plaza

University of Georgia

Athens, GA 30602

(706) $542-1355$

(706) $542-6587$ (Fax)

Kathleen S. Smith has directed the TA Program for the Office of Instructional Support and Development at the University of Georgia since 1990 and the International Fellows Program since 1997. In collaboration with the honor's program, she directs the FIPSE-sponsored CURO TA program to encourage graduate students to mentor undergraduate research projects. Her research includes a longitudinal study of the career path of participants in the ten-year-old TA mentor program. The decade-old study includes data documenting the influence of graduate preparation on career choices and the transition into a faculty position. She gardens and sails for relaxation and is working on a novel about life in academia which parallels her research interests. 